\title{
Use and Impact of Artificial Intelligence on Climate Change Adaptation in Africa
}

\author{
Isaac Rutenberg, Arthur Gwagwa, and Melissa Omino
}

\section{Contents}

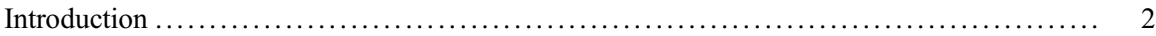

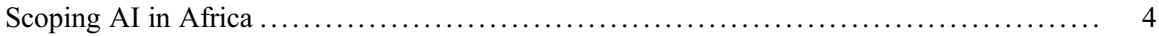

Case Studies of General Applications of AI in Africa ............................. 5

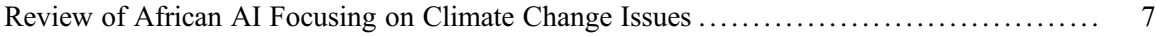

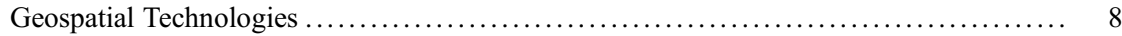

The Private Sector, and Converging Exponential Technologies ................... 10

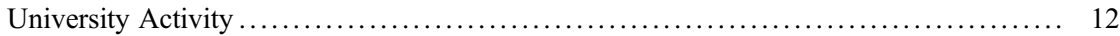

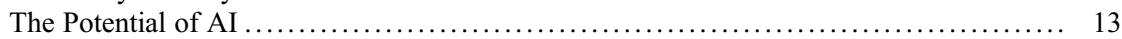

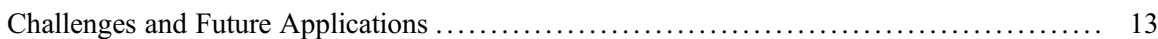

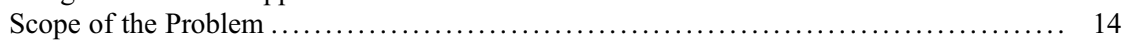

Ethical Issues of Predicting Climate Change Impacts .......................... 14

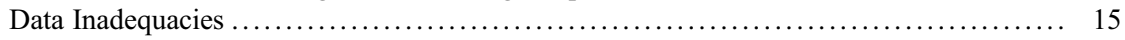

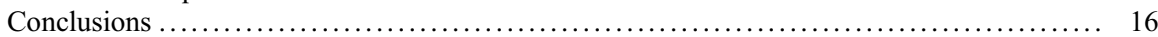

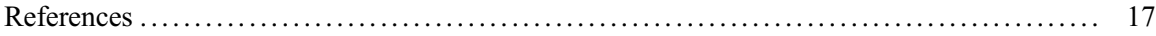

\begin{abstract}
Although Climate Change is a global phenomenon, the impact in Africa is anticipated to be greater than in many other parts of the world. This expectation is supported by many factors, including the relatively low shock tolerance of many African countries and the relatively high percentage of African workers engaged in the agricultural sector. High-income countries are increasingly turning their focus to climate change adaptation, and Artificial
\end{abstract}

This chapter was previously published non-open access with exclusive rights reserved by the Publisher. It has been changed retrospectively to open access under a CC BY 4.0 license and the copyright holder is "The Author(s)". For further details, please see the license information at the end of the chapter.

I. Rutenberg $(\bowtie) \cdot$ A. Gwagwa $\cdot$ M. Omino CIPIT, Strathmore University, Nairobi, Kenya

e-mail: irutenberg@strathmore.edu 
Intelligence (AI) is a critical tool in those efforts. Algorithms using AI are making better predictions on the short- and long-term effects of climate change, including predictions related to weather patterns, floods and droughts, and human migration patterns. It is not clear, however, that Africa is (or will be) maximally benefitting from those AI tools, particularly since they are largely developed by highly developed countries using data sets that are specific to those same countries. It is therefore important to characterize the efforts underway to use AI in a way that specifically benefits Africa in climate change adaptation. These efforts include projects undertaken physically in Africa as well as those that have Africa as their focus. In exploring AI projects in or about Africa, this chapter also looks at the sufficiency of such efforts and the variety of approaches taken by researchers working with AI to address climate change in Africa.

\section{Keywords}

Africa $\cdot$ Climate change $\cdot$ Artificial intelligence $\cdot$ Algorithms $\cdot$ Data $\cdot$ Adaptation $\cdot$ Migration

\section{Introduction}

The deepest roots of climate change begin with the second industrial revolution and the widespread adoption of fossil fuel-based machinery. As the world enters the fourth industrial revolution, the adoption of advanced technologies such as artificial intelligence (AI) introduces complex challenges and opportunities for the nowinevitable and as-yet-undetermined issues of climate change. This chapter explores those challenges and opportunities, and whether or to what extent the fourth industrial revolution will enhance Africa's ability to cope with climate change.

Technologies associated with the fourth industrial revolution (4IR) include blockchain, the Internet of things (IoT), artificial intelligence, cloud computing, quantum computing, advanced wireless communications, and 3D printing, among others. Although these technologies are, at times and in various ways, interrelated, this chapter focuses mainly on AI and the impact that it will have on Africa's ability to cope with climate change. This focus is not, however, meant to imply that other 4IR technologies will not be important. Indeed, some technologies such as the widespread connectivity of sensors that accompany the development of IoT will likely have substantial positive impact on the ability of African nations to gather useful data. An example of this is Upepo Technologies, described below, that is using IoT devices to monitor water distribution points throughout Kenya. Other technologies may have mixed or negative impact: cryptocurrencies based on blockchain technology have so far increased the amount of energy used worldwide by computers, and advanced communications technologies are projected to account for $20 \%$ of global energy demand by 2025 (The Guardian 2017). Any increase in energy demand has a negative effect on climate change. Surely these technologies will continue to evolve, and Africans' ability to predict their ultimate impacts is limited. 
AI has probably been postulated for longer than any other 4IR technology, but has remained impractical until the recent decade. Although a variety of forms of AI are known and being pursued in various contexts and by various private- and publicsector stakeholders, this chapter is largely confined to discussing AI as a tool for processing large amounts of data and improving predictions from those data.

Predictive algorithms using AI are available to entrepreneurs using two main pathways. The first is by using and adapting widely available open source algorithms. Many of the global technology companies have released suites of AI tools on open source licenses, including Google, Microsoft, and IBM. The alternative pathway is to develop, test, and train novel algorithms. Examples of companies following each of these pathways, as well as combinations thereof, can be readily identified, particularly (but not exclusively) in the high technology hubs of Lagos, Nairobi, and Johannesburg.

Developing the algorithms is, however, only one part of a larger process of integrating $\mathrm{AI}$ into products and processes. Effective predictive algorithms using AI rely on three main components: fast computers, large datasets, and abundant human labor (The Economist 2020). The need for fast computers is obvious, and suitable computing power is relatively abundantly available, even if Africa is perpetually and conspicuously absent from international lists of supercomputers (TOP500.org 2019). Human labor is needed in order to label data, as AI algorithms require accurately labelled data in order to learn and increase the accuracy of predictions. Africa has an abundance of labor, including large numbers of unemployed or underemployed youth that have sufficient computer skills, and is therefore ideally positioned for performing this task. For example, Samasource is a data annotation provider with a major presence in Kenya and Uganda. Using a hybrid structure involving both for-profit and nonprofit entities, Samasource provides data labelling services for Fortune 500 companies employing AI systems, while simultaneously seeking to reduce poverty through job creation.

This leaves three factors that are particularly interesting in the African context: the availability of sufficiently large datasets, the suitability of the algorithms themselves; and the creativity of developers, entrepreneurs, and others in applying AI in the creation of new products, services, and solutions. The three factors of interest are interrelated, and it is difficult to assess any one factor in isolation. AI is a multipurpose tool, but the output of any given AI product is as much or more dependent upon the dataset as on the specific AI algorithm. Regardless of the algorithms, the availability of high quality, locally relevant datasets is likely to be extremely important for AI to be of any use to the fight against climate change. Furthermore, since the bulk of AI development has so far been from outside the African continent, the creativity and effort of developers and their collaborators are also critical to the contribution of AI. Accordingly, the second (datasets) and third (applications) factors are the subject of this chapter.

Part I of this chapter introduced the topic and framed the research question. Part II broadly and briefly review the state of AI research and development in Africa, as well as global AI research that is relevant or targeted at Africa. Part III narrows the focus and explore African AI products and research that are specific to the issues of Climate Change. Such issues include weather prediction, agriculture, floods and drought, and 
human migration. The chapter concludes in Part IV, with a look at particular challenges and potential future applications of $\mathrm{AI}$ in the area of climate change.

\section{Scoping Al in Africa}

It is easy to get the impression that there is little or no activity in AI research and development in Africa. In report after report, African countries are either characterized as poorly performing or are complete absent from the analysis. African governments score very low in their perceived readiness to "take advantage of the benefits of AI in their operations and delivery of public services" (Oxford Insights International Development Research Centre 2019). In that global index, no African government ranked within the top 50 governments. In a broader index covering 54 countries over seven factors (Talent, Infrastructure, Operating Environment, Research, Development, Government Strategy and Commercial Ventures), all six African countries that were part of the study ranked in the bottom quartile (Tortoise Intelligence 2019). In an even broader analysis using different datasets to "comprehensively assess the state of AI R\&D activities around the world," the African region was ranked at or near the bottom of nearly every measure and ranking (Perrault et al. 2019). This included measurements such as AI papers published and cited, AI-focused patents, conferences, and technical performance. The picture painted by these global indices is one of virtually no activity and a gloomy outlook for future activity.

As is often the case, however, the global indices are not necessarily good measures of activity on the African continent. Activities by African governments and certain other entities are often not reported or described online. Activities in the private sector may be minimal when compared to activity levels in developed countries, but the comparison is not particularly useful. As shown by the examples provided below, the R\&D that is carried out is meaningful and a significant part of the overall research environment on the continent.

African-hosted conferences on AI showcase African-led and Africa-focused AI R\&D and demonstrate the breadth of such work. The Deep Learning Indaba, which began in 2017, is such an example; devoted entirely to African AI R\&D, it has doubled attendance each of the following 2 years. The yearly event has created great interest, and in 2018, 13 mini-conferences (referred to as "IndabaX" conferences) were held in as many countries in Africa. Such conferences are important for the normal reasons, but also because African researchers have particular difficulties attending AI conferences in other parts of the world. African nationals are routinely denied visas to attend international conferences (Knight 2019). The challenges faced by African nationals is significant enough that the International Conference on Learning Representations, a major AI conference, elected to hold the 2020 conference in Africa. This decision was intended to enable greater African participation (Johnson 2018).

Meanwhile, global technology companies are turning some of the focus of their AI R\&D on Africa. Google opened an AI development laboratory in Ghana in 2019. Microsoft published a whitepaper focusing on the importance of AI research in 
Africa (Microsoft Access Partnership University of Pretoria 2018). A significant body of technological developments have been produced by IBM researchers at the IBM laboratory in Nairobi (Weldemariam et al. 2020). Motivations for global technology companies to work in Africa include, among others, the reduction of bias by increasing diversity in the researchers and the context in which they work (Adeoye 2019).

\section{Case Studies of General Applications of Al in Africa}

Academic and private sector AI researchers in Africa seek to apply AI to a wide variety of topics, some of which are directly relevant to climate change, and others are relevant insomuch as they advance the general state of AI. A particularly important topic is bioinformatics and genomics (Diallo et al. 2019). Significant biodiversity exists on the African continent, and much of it is understudied relative to other regions (Campbell and Tishkoff 2008). The application of AI algorithms, with its ability to analyze large datasets, is particularly appropriate in the area of genomics. Even where the work is not specifically addressing issues directly related to climate change, a better understanding of bioinformatics and genomics will support biodiversity and our ability to encourage genetic resistance to environmental shocks.

Another topic of interest to African AI researchers is farming. The importance and vulnerability of farming on the African continent cannot be overstated. More than $50 \%$ of the entire African workforce is employed in agriculture, yet most of that activity is at the subsistence level (Alliance for a Green Revolution in Africa (AGRA) 2014). Approximately $80 \%$ of all farms in Sub-Saharan Africa are smallholder farms where 175 million people are directly employed. Modern farming methods such as large-scale mechanized harvesting, irrigation, and crop rotation are less common, meaning that African agriculture is more susceptible to weather and labor shocks. Traditional African crops are under threat from global seed companies seeking to dominate the African market (Scoones and Thompson 2011). Deforestation and overgrazing threaten African soil, but productive farmland is targeted by foreign governments and companies seeking new resources to enhance food security (The World Bank 2014).

It is anticipated that predictive analytics, aided by machine learning, will significantly improve overall output by the African farming sector (Alliance for a Green Revolution in Africa (AGRA) 2014). The cornerstone of successful AI is sufficient data, and in this area, Africa is relatively well positioned. Datasets pertaining to agriculture are available from a variety of sources, as the subject of African agriculture has been of intense interest to both local and international stakeholders for many decades. These datasets include actual measurement data as well as predictive or extrapolative datasets, as well as combinations thereof (African Soil Information Service). Improving the quantity and quality of data, and encouraging wider and more effective use of Big Data, is the focus of research by Patrick MacSharry at the Carnegie Mellon University campus in Kigali, Rwanda. Numerous 
other academic researchers are also contributing to the push toward effective incorporation of data science in African agriculture.

Successful agriculture requires more than land, seeds, and suitable weather. Crop diseases and infestations of plant pests are significant threats to global agriculture and are particularly dangerous to agriculture in Africa. For example, invasions of the desert locust can last for up to a decade, and can cause widespread food shortages of catastrophic proportions (Lecoq 2003). Similarly, strains of wheat rust such as ug99, which originated in Uganda, are considered a global threat as well as a threat to African agriculture (Aydoğdu and Boyraz 2012). An ability to diagnose crop diseases is therefore critical, and local and global technology industries have taken notice. Mobile phone applications that allow farmers to diagnose crop disease or identify the presence of crop pests are proliferating (Nzouankeu 2019). Considering that many plant diseases and crop pests are highly geographically specific, local development of technology solutions to these problems is a prerequisite to their success, and the African technology industry is beginning to address this need.

Looking beyond agriculture, financial institutions in Africa are not often at the forefront of widespread introduction and adoption of technology. Notwithstanding the success of mobile banking (which more properly attributes success to the fact that it originated from the telecom industry rather than the banking industry), traditional financial institutions have been slow to adopt technologies such as online banking. This is not necessarily only due to resistance within the African banking sector, but is also due to the relatively low level of access to technology by banking customers. Nevertheless, nearly every industry sector in Africa is affected by the availability (or absence) of credit and the presence (or absence) of financial institutions. Financial technologies, referred to as "fintech," are a particularly active area of the incorporation of $\mathrm{AI}$ into products and services. A common use of $\mathrm{AI}$ in fintech is in the determination of creditworthiness. Although not discussed here, it is worth noting that such applications have been criticized for a variety of reasons, ranging from data protection issues to exacerbation of inequality (Johnson et al. 2019). Traditional and nontraditional banking institutions can make use of larger datasets from a broader list of sources in order to determine the risk of extending credit to individual or institutional customers. This is particularly useful in a region where formal credit histories are relatively rare or based on very limited data. Another fintech product that is gaining traction with African financial institutions is the use of AI to evaluate customer behavior. Behavior analysis can be used to improve predictions of suitable financial products, thus allowing institutions to focus their marketing efforts and improve efficiencies.

Raising capital to support product development and market expansion is a necessary component of the modern technology industry. There is significant evidence that success at attracting investor attention in Africa is due to a variety of factors, including some factors that are not related to the quality or appropriateness of the technology (Peacock and Mungai 2019). Nevertheless, some African startups have raised significant capital for the application of AI to agriculture, fintech, and mobility solutions, among other uses of AI. In South Africa, Aerobotics is a company that is developing a digital platform for using AI to interpret data gathered 
by drones and satellites. The data interpretation algorithms are targeted at detecting plant pests and diseases. Apollo Agriculture is a Kenyan company using AI to interpret satellite data, soil data, farmer behavior, and crop yield models. The data interpretation algorithms allow the company to offer farmers customized financing as well as customized seed and fertilizer packages (Nanalyze 2019).

In view of the above examples and others not mentioned, there is clearly activity in AI R\&D in Africa. It may be that the activity is minimal when compared with that of developed countries, but there is a very high level of interest in AI technologies by governments, academia, and the private sector, and activity levels will surely increase with time.

Having reviewed the general state of AI R\&D in Africa, and having established that there is ongoing interest and activity in applying AI to a variety of fields, this chapter now turns to the specific application of AI to climate change.

\section{Review of African Al Focusing on Climate Change Issues}

By 2050, it is widely expected that hundreds of millions of people in developing countries will have left their homes as a result of climate change - a mass displacement that will make already-precarious populations more vulnerable and impose heavy burdens on the communities that absorb them. Unfortunately, the world has barely begun to prepare for this impending crisis.

According to the World Politics Review, those displaced by climate change are neither true refugees nor traditional migrants, and thus occupy an ambiguous position under international law. Consequently, the world needs to agree on how to classify environmental migrants, as well as what their rights are. It also needs to strengthen its capacity to manage these mass migrations, without weakening existing international regimes for refugees and migrants (Patrick 2020).

Similarly, international organizations, such as the United Nations, as well as industry and social society are exploring technological solutions including the development of tools and technologies that leverage data sources from radio content, social media, mobile phones and satellite imagery, and technology toolkits. These toolkits can enhance decision-making by providing real-time situational awareness for project and policy implementation. The trend is moving towards a converging of exponential technologies (AI, robotics, drones, sensors, and networks). Although there is growing criticism of this trend toward 'technologizing of care', which can conflict with the centrality of the humanitarian principles, these technologies, in particular AI, have the potential to help Africa to be better prepared to thwart the effects of climate change, both through mitigation and adaptation.

In light of this, this section examines the use of AI that is being (or could be) used in Africa for any aspect of climate change such as weather prediction, agriculture, human migration, floods and droughts. These projects could be undertaken physically in Africa as well as in those countries that have Africa as their focus, and those that can be adapted to Africa. It assumes a broader definition of AI which includes the use of "software (and possibly also hardware) systems designed by humans that, 
given a complex goal, act in the physical or digital dimension by perceiving their environment through data acquisition, interpreting the collected" (European Commission High-Level Expert Group on Artificial Intelligence 2018). It examines how a combination of technologies work together, including geospatial technologies, converging technologies such as robotic responders, swarm technology, and aerial drones which may also rely on geospatial data. Further, it also examines AIdriven platforms that crowdsource first-hand experiential data from those on the ground, and how these technologies could potentially transform disaster relief methods in Africa. Finally, it examines the issue of mobile connectivity and wireless networking trends and how improving these can give a newfound narrative power to those most in need. Although some of the projects examined in this section do not directly address climate change, per se, they may address other environmental concerns that are relevant to climate change.

\section{Geospatial Technologies}

Africa has seen a steady increase in multi-stakeholder geospatial initiatives in recent years and these include those sponsored by the UN agencies, Public Private Partnerships, and initiatives led by international organizations and industry, especially global technology companies such as Google and Vodafone.

\section{UN Agencies}

The UN, in particular its data science arm, the Global Pulse, has been working to support African governments to achieve the U.N. 2030 Agenda for Sustainable Development. The Global Pulse, working from its Kampala Lab in Uganda, has led the work to develop numerous toolkits that consolidate it as an important technical arm of the UN network (Pulse Lab Kampala 2018). These pieces of software are a key in informing the SDGs through big data, data science and artificial intelligence because they aggregate, anonymize, combine, analyze, and visualize data. During 2016 and 2017 the Lab has both created brand-new toolkits and adapted previously developed ones for new projects. This has been part of a bigger project under which, between 2016 and 2017, the Pulse Lab Kampala worked with various $\mathrm{UN}$ agencies and development partners in Uganda and the region to test, explore and develop 17 innovation projects. The Lab also furthered the development of tools and technologies that leverage data sources from radio content, social media, mobile phones and satellite imagery, and created technology toolkits. These toolkits can enhance decision-making by providing real-time situational awareness for project and policy implementation (Pulse Lab Kampala 2018).

The Pulse's projects sit in the current global policy shift which emphasizes technological tools as opposed to their application to improving knowledge about climate change. This is even reflected in the secondary school geography curriculum which has seen an introduction of GSI in some African countries (Cox et al. 2014). This shift is borne from the premise that geospatial technologies, synergetic applications of remote sensing, and geographical information systems, offer versatile 
cross-scale tools to study long term climate changes, and their impacts on social- and ecological systems.

According to the UN World Data Forum, the U.N. 2030 Agenda for Sustainable Development requires countries to be chiefly responsible for collecting information and monitoring progress towards achieving economic, social, and environmental sustainability (United Nations World Data Forum 2018). For instance, the UN World Data Forum has held sessions to enable the sharing of sound Earth Observation (EO) methods, tools, and technologies, as well as national use cases of effective integration of EO and geospatial data products with traditional and other relevant information sources in support of the Sustainable Development Goals (SDGs), targets, and indicators, and for informed decision-making. Some of the technologies discussed at such forms include the African Regional Data Cube, aimed to enable greater use of EO and geospatial data for sustainable development (Anderson et al. 2017).

To strengthen its work at policy level in this area, in 2019, the UN Pulse has been engaging African AI experts to lead efforts to draft a Code of Ethics for the use of AI-supported systems in humanitarian and development contexts (International Telecommunication Union 2019). Once developed, the Code may be used as guidance for the work at Global Pulse and at other UN organizations deploying AI for social good and to ensure the deployment of such technologies is both ethical and human rights respecting.

\section{Public-Private Partnerships}

Similarly, the private sector has been working with governments on data science projects that leverage data for AI applications in humanitarian contexts. For instance, the Vodafone Foundation pioneered a program in Ghana to use aggregated anonymized data to help the government track and control epidemics to prevent widespread outbreaks (Vodafone 2018). The program, dubbed as one of the first of its kind globally, tracks and analyzes real-time trends in population movement. The program demonstrates the use of big data in situations directly relevant to climate change. The Ghana initiative is a good example of a multistakeholder approach to technology deployment for humanitarian ends as it is not only supported by Vodafone Ghana but also the Flowminder Foundation, an NGO that provides insights, tools and capacity-strengthening to governments as well as international agencies and NGOs (GhanaWeb 2019).

The South Africa company Aerobotics, mentioned above, operates a public private partnership that utilizes aerial imagery and machine learning algorithms to solve specific problems across some industries including insurance and agriculture. In May 2019, Aerobotics signed an agreement with Agri SA to offer free service for all South African farmers (Lukhanyu 2019). Drones are used to track tree health and size, using multispectral, high resolution imagery. The project also enables farmers to identify areas needing attention from historical satellite health data, and inspect these in the field using a mobile app. The Aerobotics project is supported by the South African Department of Environmental Affairs (DEA) which works with the Committee on Spatial Information (CSI) and the broader GIS community to define the data architecture, systems, standards, policies and processes for a fully integrated 
and effective spatial data infrastructure for the country. The Environmental Geographical Information Systems (E-GIS) webpage provides access to baseline environmental geospatial data, map services, printable maps and relevant documents to users of geospatial technology, government, and the public (Department of Environmental Affairs South Africa 2016).

Another example, also out of South Africa, applies machine learning to the issue of air quality prediction (Chiwewe and Ditsela 2016). Stemming from the Green Horizons initiative, IBM researchers partnered with Chinese government researchers for the purpose of building air quality prediction software. In Johannesburg, the work is to adapt the air quality prediction software to the local context. The Green Horizon's system harnesses historical and real time data about weather, air quality, topography, and traffic reports to build predictions about air quality. The project's South Africa lead, Tapiwa Chiwewe, says that the task is to tweak the software to local particularities. For instance, Johannesburg does not have the dense network of air quality monitoring stations (eight stations compared to 35). Chiwewe and the team of researchers sought to 'teach' the software to work with more sparse data and to use intermediate fixes to make up for the lack of data.

\section{The Private Sector, and Converging Exponential Technologies}

\section{International Organizations \& Global Technology Companies}

Globally, converging exponential technologies (AI, robotics, drones, sensors, networks) are transforming the future of disaster relief (Diamandis 2019). African stakeholders have been experimenting with these technologies in a variety of contexts. These efforts have been led by international organizations such as Omdena and Element AI, working with local African NGOs like R365 and the Nigerian NGO Renewable Africa (Adewumi 2020). Academic institutions and global technology companies such as Google also play a part in this work, which span the R\&D process as well as prototyping and implementation. For example, the Canadian based Element AI has African-focused projects that support the use of robots for humanitarian purposes. Their intention is to develop human-machine collaborations that build up a trusted relationship with AI products and services already available. Two further examples are illustrative. Atlas AI, a Silicon Valley public benefit corporation, has teamed with the Alliance for a Green Revolution in Africa (AGRA), to apply predictive analytics and machine learning to help process numerous datasets in an effort to improve smallholding farming output (AGRA 2019). Pennsylvania State University developed, deployed, and continue to upgrade PlantVillage, a mobile application that uses an AI tool to diagnose crop diseases in Africa (Penn State 2019).

Global initiatives inspired by Kenya's Ushahidi are emerging that leverage AI, crowd sourced intelligence, and cutting-edge visualizations to optimize crisis response (Starbird 2012). Such projects include One Concern (2020), which employs AI in analytical disaster assessment and damage estimates. Crowdsourced intelligence (which includes predictive crisis mapping and AI-powered responses) is used in response to both natural disasters and humanitarian disasters. An open- 
source crisis-mapping software developed by Ushahidi is used for real-time mining of social media, news articles, and geo-tagged, time-stamped data from countless sources (Meier 2012). As mobile connectivity and abundant sensors converge with AI-mined crowd intelligence, real-time awareness will only multiply in speed and scale (Diamandis 2019).

Other organizations are using similar crowdsourcing technologies to address different challenges, but such technologies are also helpful in understanding agricultural and other environment concerns. IBM's Hello Tractor is an open source mobile platform that enables farmers to access tractor services on demand (Assefa 2018). By using technology integrated from partners like the IoT companies Aeris and CalAmp, the platform can tell when a tractor is turned on and how far it travels. By using the platform, over the next 5 years, through a public-private partnership, John Deere plans to deploy 10,000 tractors in Nigeria, selling them to contractors who then rent them out to small farmers (Peters 2018). Considering that climate change is expected to increase uncertainty in the long-term viability of agricultural land, the availability of tractors for rent will be critical as a means for improving flexibility of farmers.

Another organization using AI-based crowdsourcing solutions to climate-related or climate-relevant challenges is Omdena, which sources ideas to respond to local challenges. Several of Omdena's projects are worth discussion. Under one of its challenges, 34 collaborators working together with the UN Refugee Agency (UNHCR) built several AI and machine learning solutions to predict forced displacement, violent conflicts, and climate change effects in Somalia (Omdena 2019). Their community of AI experts and data scientists have developed several solutions to predict climate change and forced displacement in Somalia, where millions of people are forced to leave their current area of residence due to natural and manmade disasters such as droughts, floods, and violent conflicts. This is a holistic project under which Omdena's challenge partner, UNHCR, provides assistance and protection for those who are forcibly displaced inside of Somalia. The findings will help UNHCR improve speed and efficiency of responses to such disruptions.

In a second project, Omdena's collaborators analyze conflict data to build a hot zone representation, which predicts the most dangerous locations and the highest fatalities (Omdena 2019). The machine learning model can help to optimize the allocation of utility personnel to handle incidents. A promising application of this technology is to leverage satellite images to assess the environmental impact of forced displacement and conflict by comparing the weekly Vegetation Health Index with human displacement data.

Omdena's projects are also focused on increasing the adoption of renewable energy, an important component of climate change mitigation. In Nigeria, Omdena's AI community built an interactive map showing the top Nigerian regions for solar power instalments (Adewumi 2020). The solutions will provide helpful insights for government and policy makers to make decisions on where to allocate resources in the most effective way. In a country where more than 100 million people lack stable access to electricity, renewable energy must be a major part of any environmentally friendly solution. The Omdena community generated a variety of outputs, including 
a grid coverage analysis and machine-learning-driven heatmaps to identify sites that are most suitable for solar panel installation. Along with an interactive map listing the top Nigerian regions in terms of demand for electricity, such tools are helpful for those seeking to survey and validate locations before installing solar panels. This will enable data-driven investments and policy-making and potentially impact the lives of many people in Nigeria.

A particularly forward-looking initiative is the Microsoft AI for Earth grant program. One of the recipients of the grant is Upepo Technology, a Kenyan company that plans to use the grant in a water monitoring project. The company is deploying a large network of IoT devices, and employing AI algorithms to analyze the data from sensors monitoring reservoirs, boreholes, water kiosks, individual taps, and other water points. Considering the substantial impact that climate change has on issues pertaining to water - particularly by changing the patterns of precipitation - an enhanced ability to monitor water usage, wastage, and storage will greatly benefit the ability to deal with climate change impacts.

\section{University Activity}

African universities and academic institutions are also setting up AI technologybased projects to tackle environmental issues, including Makerere University in Uganda and Carnegie Mellon University in Kigali, which was the first to offer a Master of Science Degree in Electrical and Computer Engineering with hands-on courses which include machine learning, robotics, and the internet of things (Carnegie Mellon University Africa). A few such projects are discussed below.

\section{AirQo}

The Makerere University Artificial Intelligence Research Group (AIR Lab) specializes in the application of artificial intelligence and data science to challenges common in the developing world. AIR Lab received support from the Pulse Lab to set up AirQo - an air quality data monitoring, analysis and modelling platform in East Africa meant to achieve clean air for all African cities through leveraging data (Nabatte 2019). AirQo is deploying a growing network of low-cost air quality monitors. Using machine learning and artificial intelligence to collect and analyze data, the project makes air quality predictions useful in raising awareness and informing policy decisions. Future research plans include the development and deployment of machine learning methodology to analyze air pollution data from Kampala, in order to determine the source of the pollution and to aid the design of mitigating interventions.

\section{WIMEA-ICT}

WIMEA-ICT is a combined research and capacity building project that seeks to improve weather information management in the entire East Africa region by development of ICT-based solutions (Norwegian Agency for Development Cooperation [NORAD] 2013). Funded by the Norwegian Agency for Development 
Cooperation (Norad) under the NORHED (Norwegian Programme for Capacity Development in Higher Education and Research for Development) scheme, the project is a cooperation between Makerere University in Uganda, Dar es Salaam Institute of Technology (DIT) in Tanzania, the University of Juba in South Sudan, and the Geophysical Institute of the University of Bergen.

The project recognizes the wide-ranging importance of weather data and the problems that result when weather predictions are inaccurate. Although project documentation does not specify the use of AI, among the five components of the project at least one is ideal for incorporation of $\mathrm{AI}$ : development of numerical weather prediction models specifically designed for the East African context.

\section{The Potential of Al}

It is not difficult to identify a long list of research projects that focus on various climate change issues in Africa. Many such projects include analyses of large datasets that would, seemingly, be ideal for analysis by AI algorithms. For example, Petja et al. (2004) describe an analysis of South African regional weather data dating from 1900 onward and satellite data dating from 1985 onward. The data are used to monitor regional climate and vegetation variations over time. In another example, Hagenlocher et al. (2014) describe the combination of numerous datasets to develop a cumulative climate change impact indicator. Applied to sub-Saharan Africa, the authors identified, evaluated, and mapped 19 hotspots that exhibited the most severe climate changes. In research out of Stanford University, Burke and Lobell (2017) demonstrated the importance of high-resolution satellite imagery data to estimate and understand yield variation among smallholder African farmers. This understanding generates various potential capabilities including the inexpensive measurement of the impact of specific interventions, the broader characterization of the source and magnitude of yield gaps, and the development of financial products aimed at African smallholders.

Although the immediately foregoing examples, and many other studies, do not specifically mention the use of AI, it is clear that large interrelated datasets are of vital importance to many different areas of research relevant to climate change. There is significant room for AI to be used by researchers to improve methodologies involving analysis of weather and other data (Rasp et al. 2018).

\section{Challenges and Future Applications}

Development of advanced technologies typically encounters challenges, and AI technologies and applications with a focus on climate change are no exception. Besides the typical challenges of developing AI products and services, Africa presents unique challenges both technological and political/ethical. 


\section{Scope of the Problem}

Technologies powered by machine learning (ML) algorithms, including those discussed herein that aid climate analysis (Huntingford et al. 2019), have advanced dramatically, triggering breakthroughs in other research sectors. Although a considerable number of isolated Earth System features have been analyzed with ML techniques, more generic application to understand better the full climate system has not occurred, and the technology to do so may be quite far from the current state of development. At this stage of development, Artificial intelligence (AI) can be used to analyze smaller systems and provide enhanced warnings of approaching weather features, including extreme events. ML and AI can aid in understanding and improving existing data and simulations, as it has done in other systems (Huntingford et al. 2019). For instance, Airbus Defence and Space is using TensorFlow, the open-source set of AI tools from Google, to extract information from satellite images and offer valuable insights to customers. In a similar manner, AI can be used to detect and analyze isolated Earth System features and climate patterns, especially with the latest release of TensorFlow Quantum which enables a faster prototyping of ML models. Nevertheless, modeling the entire global climate remains challenging, and predictions from such models vary at all scales. Until the computational power and models have been refined to enable accurate global predictions, the need remains for smaller scale models. Local modeling requires context specific data and algorithms, so efforts toward development of Africa-specific climate change models must continue to be encouraged.

\section{Ethical Issues of Predicting Climate Change Impacts}

AI algorithms are well suited to analyze large datasets and detect patterns, so they are naturally well suited for looking at patterns of large-scale human movement and the data that might be associated with such movement (Beduschi 2020). For example, it is postulated that economic data such as GDP growth, along with trends in other data such as population growth and weather data (which might indicate food security issues), can be used to predict future large-scale human migration (Nyoni 2017). Accuracy of the predictions can be increased by incorporating real-time data points, such as announcements by government central banks, military actions, and weather observations.

Assuming there is a reasonable level of accuracy, predicting the location or the country most likely to suffer the next crisis of human migration has both remedial and prophylactic uses (TEDx Talks 2016). Humanitarian organizations can begin preparations for dealing with the crisis, and intergovernmental financial institutions can consider policy measures to ease debt burdens or encourage growth. Local and national governments of the yet-to-be affected regions can take measures to calm tensions and address the issues that cause migration. As useful as such predictions may be, this use case raises extreme ethical issues, for example by encouraging international efforts (including both active and passive efforts) to promote regime 
change where a specific government's policies appear to be leading to a future migratory crisis. Additionally, a prediction of a future migratory crisis may be a self-fulfilling prophecy, by increasing tension among the population and reducing investor confidence in the economy. The good intentions of those developing the technology, in this case, may increase the likelihood of the humanitarian disasters that they are seeking to ease.

\section{Data Inadequacies}

Apart from ethical issues, the development of AI for combating climate change in Africa may be severely hampered by a lack of data. The concept of a digital divide is many decades old, and documentation of the digital divide separating Africa from other regions is well established (Karar 2019). The modern-day extension of this concept is that of a data divide (Castro 2014), also referred to as a data desert or data poverty. First recognized with respect to certain populations in developed countries, the data divide is a problem in Africa and with respect to climate change for a variety of reasons. Historical weather data is less extensive in Africa compared with other parts of the world (Dinku 2018). Current data is also less extensive, as there are fewer weather satellites monitoring Africa than other regions and ground-based sensing is also less extensive (Dinku et al. 2011).

Even where there is historical climate data, those data may be inaccessible - for example, because African governments and their weather agencies are increasingly seeking to commercialize the data, or because the data are not digitized (Nordling 2019). In this context, the issue of a data divide is complex and is indicative of an uneven power dynamic. As with many other areas, Africa engages the rest of the world from a disadvantaged position, and the unbalanced power of the relationship may negatively affect the outcome. Whereas monetizing data is a common practice in developed countries, because African nations need significant help in building the infrastructure for collecting data, they are expected to willingly release the data. A data commons, in which climate data is readily available for all to use, is vitally important to help climate scientists and other interested parties understand the impacts of climate change in Africa. Nevertheless, the desire of data holders to seek ways of monetizing their data is understandable.

The concept of Africa as a data desert may, therefore, be unfairly characterizing the true situation. Rather than an absence of data, as the desert analogy implies, it is probably more accurate to say that data are present but not as readily available or easily searchable. As mentioned previously, African government websites may lack updated data (Ndongmo 2016), but this does not mean that they are not collecting the data. Open data portals are present in a few countries but have not become mainstream methods for governments to disseminate datasets. In some cases, governments generate revenue by selling datasets, and therefore have little incentive to making them available on an open platform. Efforts at increasing the volume of data collected about Africa should take into account these issues. 
Regardless of the causes of the data divide, there is no doubt that insufficient data is important in Africa's ability to adapt to climate change. Climate change does not affect all geographical locations equally (United States Environmental Protection Agency (USEPA) 2017). As the global average temperature rises, and sea levels rise, average temperatures in some areas may decline. Overall rainfall may increase or decrease in any particular location, depending on a variety of factors. Extremes in precipitation and temperatures will also be in homogeneously affected. These variations would be less problematic if data were gathered with uniform consistency in all locations, but as mentioned previously, data collection in Africa is less consistent and less thorough. The result of this situation is likely to be less accurate predictions of the effects of climate change in Africa compared with other regions. Less accurate predictions may mean that local and international decision makers are unable to adequately prepare for the impacts of climate change.

Whether due to inefficient dissemination or to a fundamental lack of collection, or to some other reasons, the lack of available data has severe implications for the use of AI in adapting to climate change. Without sufficient data, AI algorithms are substantially less accurate and useful (West and Allen 2018). The trend in Africa, however, appears to be shifting toward a wider availability of data and a greater effort toward utilizing all available tools, including AI, in addressing climate change issues.

\section{Conclusions}

Some countries are serious in their look toward the future. For example, Ethiopia launched its first observatory satellite into space in 2019. The 70-kg remote sensing satellite is to be used for agricultural, climate, mining and environmental observations, allowing the Horn of Africa to collect data and improve its ability to plan for changing weather patterns for example. The satellite will operate from space around $700 \mathrm{~km}$ above the surface of earth. Developments in Ethiopia follow the introduction by the African Union of an African space policy, which calls for the development of a continental outer-space program and the adoption of a framework to use satellite communication for economic progress. Clearly, efforts such as this are forward thinking and will help the continent to address the lack of data that hampers the use of AI to address issues of climate change.

The problems of climate change are global, but Africa is likely to suffer to a greater degree compared with other regions. Scientists and policymakers in Africa need every available tool to help the continent adapt to the changes, but should always keep in mind the severity and scale of the problem. Notwithstanding the benefits that AI clearly brings, or promises to bring, in the efforts to adapt to climate change, it is clear that the fourth industrial revolution cannot fix what the second industrial revolution started. 


\section{References}

Adeoye A (2019) Google has opened its first Africa Artificial Intelligence lab in Ghana. https://edition.cnn.com/2019/04/14/africa/google-ai-center-accra-intl/index.html. Accessed 16 Mar 2020

Adewumi AE (2020) AI for the people: how to stop the Nigerian energy crisis. https://omdena.com/ blog/ai-energy-crisis. Accessed on 15 Mar 2020

African Soil Information Service, AfSIS. http://africasoils.net/. Accessed on 15 Mar 2020

Alliance for a Green Revolution in Africa (AGRA) (2014) Africa agriculture status report 2014: climate change and smallholder agriculture in sub-saharan Africa, AGRA Report. Nairobi. https://hdl.handle.net/10568/42343. Accessed on 16 Mar 2020

Alliance for a Green Revolution in Africa (AGRA) (2019) New partnership to boost food security in Africa by use of artificial intelligence. http://agra.org/new-partnership-to-boost-food-securityin-africa-by-use-of-artificial-intelligence. Accessed on 14 Mar 2020

Anderson K, Ryan B, Sonntag W, Kavvada A, Friedl L (2017) Earth observation in service of the 2030 agenda for sustainable development. Geo Spat Inf Sci 20(2):77-96. https://doi.org/ $10.1080 / 10095020.2017 .1333230$

Assefa S (2018) IBM Research, Hello Tractor pilot agriculture digital wallet based on AI and blockchain. https://www.ibm.com/blogs/research/2018/12/hello-tractor/. Accessed on $16 \mathrm{Mar}$ 2020

Aydoğdu M, Boyraz N (2012) Stem rust (ug99), seen as a threat globally. Akden iz Univ Ziraat Fak Derg 25(1):23-28. https://www.researchgate.net/publication/305687716_Stem_rust_ug99_ seen_as_a threat globally. Accessed on 16 Mar 2020

Beduschi A (2020) International migration management in the age of artificial intelligence. Migr Stud. https://doi.org/10.1093/migration/mnaa003

Burke M, Lobell DB (2017) Satellite-based assessment of yield variation and its determinants in smallholder African systems. Proc Natl Acad Sci U S A 114(9):2189-2194. https://doi.org/ 10.1073/pnas.1616919114

Campbell M, Tishkoff S (2008) African genetic diversity: implications for human demographic history, modern human origins, and complex disease mapping. Annu Rev Genomics Hum Genet 9:403-433. https://doi.org/10.1146/annurev.genom.9.081307.164258

Carnegie Mellon University Africa. https://www.africa.engineering.cmu.edu/. Accessed on 17 Mar 2020

Castro D (2014) The rise of data poverty in America. Report from Center for Data Innovation. Available at: http://www2.datainnovation.org/2014-data-poverty.pdf. Accessed on 13 Mar 2020

Chiwewe T, Ditsela J (2016) Machine learning based estimation of ozone using spatio-temporal data from air quality monitoring stations. Paper presented at the 14th International Conference on Industrial Informatics, Poitiers, France, 18-21 July 2016. https://doi.org/10.1109/ INDIN.2016.7819134

Cox H, Kelly K, Yetter L (2014) Using remote sensing and geospatial technology for climate change education. J Geosci Educ 62(4):609-620. https://doi.org/10.5408/13-040.1

Deep Learning Indaba. http://www.deeplearningindaba.com. Accessed on 16 Mar 2020

Department of Environmental Affairs South Africa (2016) Welcome to environmental GIS. https://egis.environment.gov.za/. Accessed on 16 Mar 2020

Diallo AB, Nguifo EM, Dhifli W, Azizi E, Prabhakaran S, Tansey W (2019) Selected papers from the workshop on computational biology: joint with the international joint conference on artificial intelligence and the international conference on machine learning 2018. J Comput Biol 26:6. https://doi.org/10.1089/cmb.2019.29020.abd

Diamandis P (2019) AI and robotics are transforming disaster relief. https://singularityhub.com/ 2019/04/12/ai-and-robotics-are-transforming-disaster-relief/. Accessed on 17 Mar 2020

Dinku T (2018) Overcoming challenges in the availability and use of climate data in Africa. ICT Update. https://ictupdate.cta.int/en/article/overcoming-challenges-in-the-availability-anduse-of-climate-data-in-africa-sid06fd8a811-e179-4fa5-9c8f-806bd2f27c3e. Accessed on 13 Mar 2020 
Dinku T, Asefa K, Hilermariam K, Grimes D, Connor S (2011) Improving availability, access and use of climate information. World Meteor Org Bull 60(2) Available at: https://public.wmo.int/en/bulletin/improving-availability-access-and-use-climate-information. Accessed on 16 Mar 2020

European Commission High-Level Expert Group on Artificial Intelligence (2018) The ethics guidelines for trustworthy artificial intelligence. https:/ec.europa.eu/digital-single-market/en/ high-level-expert-group-artificial-intelligence. Accessed on 16 Mar 2020

GhanaWeb (2019) GSS partners Vodafone \& Flowminder to produce reliable data for sustainable development. https://www.ghanaweb.com/GhanaHomePage/NewsArchive/GSS-partnersVodafone-amp-Flowminder-to-produce-reliable-data-for-sustainable-development-814189.

Accessed on 17 Mar 2020

Hagenlocher M, Lang S, Hölbling D, Tiede D, Kienberger S (2014) Modeling hotspots of climate change in the Sahel using object-based regionalization of multidimensional gridded datasets. IEEE J Sel Top Earth Obs Remote Sens 7(1):229-234. https://doi.org/10.1109/ JSTARS.2013.2259579

Huntingford C, Jeffers E, Bonsall M, Christensen H, Lees T, Yang H (2019) Machine learning and artificial intelligence to aid climate change research and preparedness. Environ Res Lett 14 (12):124007. https://doi.org/10.1088/1748-9326/ab4e55

International Telecommunication Union (2019) United Nations activities on artificial intelligence. Compendium presented and discussed at the AI for Good UN Partners Meeting, UNWomen Headquarters in New York, 23 September 2019. https://www.itu.int/dms_pub/itu-s/opb/gen/SGEN-UNACT-2019-1-PDF-E.pdf. Accessed on 16 Mar 2020

Johnson K (2018) Major AI conference is moving to Africa in 2020 due to visa issues. https://ven turebeat.com/2018/11/19/major-ai-conference-is-moving-to-africa-in-2020-due-to-visa-issues/. Accessed on 16 Mar 2020

Johnson K, Pasquale F, Chapman J (2019) Artificial intelligence, machine learning, and bias in finance: toward responsible innovation. Fordham Law Rev 88(2):499. https://ir.lawnet.fordham. edu/flr/vol88/iss $2 / 5$. Accessed on 12 Mar 2020

Karar H (2019) Algorithmic capitalism and the digital divide. J Dev Soc 35(4):514-537

Knight W (2019) African AI experts get excluded from a conference - again. https://www.wired. $\mathrm{com} /$ story/african-ai-experts-get-excluded-from-a-conference-again/. Accessed on 16 Mar 2020

Lecoq M (2003) Desert locust threat to agricultural development and food security and FAO/ International role in its control. Arab J Pl Prot 21:188-193. https://www.researchgate.net/ publication/242118174_Desert_Locust_Threat_to_Agricultural_Development_and_Food_ Security_and_FAOInternational_Role_in_its_Control. Accessed on 17 Mar 2020

Lukhanyu $\bar{M}$ (2019) Agri SA \& Aerobotics partner to offer free service for all South African farmers. https://techmoran.com/2019/05/15/agri-sa-aerobotics-partner-to-offer-free-service-forall-south-african-farmers/. Accessed on 16 Mar 2020

Meier P (2012) Crisis mapping in action: how open source software and global volunteer networks are changing the world one map at a time. J Map Geogr Libr 8(2):89-100. https://doi.org/ 10.1080/15420353.2012.663739. Accessed on 15 Mar 2020

Microsoft Access Partnership University of Pretoria (2018) Artificial intelligence for Africa: An opportunity for growth, development and democratisation. White Paper. https://www.up. ac.za/media/shared/7/ZP_Files/ai-for-africa.zp165664.pdf. Accessed on 14 Mar 2020

Nabatte P (2019) Mak's AirQo project is a US 1.3million Google AI impact grantee. https://news. mak.ac.ug/2019/05/maks-airqo-project-us13m-google-ai-impact-grantee. Accessed on 14 Mar 2020. See further AirQo https://www.airqo.net/. Accessed on 17 Mar 2020

Nanalyze (2019) Top-10 artificial intelligence startups in Africa. https://www.nanalyze.com/2019/ 04/artificial-intelligence-africa/. Accessed on 16 Mar 2020

Ndongmo K (2016) African government websites - new and improved, or not? Report on medium. Edition of January 8 2016. Available at: https://medium.com/@kathleenndongmo/african-gov ernment-websites-new-and-improved-or-not-746a5a5a62d. Accessed on 16 Mar 2020

Nordling L (2019) Scientists struggle to access Africa's historical climate data. Nature 574:605-606 
Norwegian Agency for Development Cooperation (NORAD) (2013) Improving weather information management in East Africa. https://norad.no/en/front/about-norad/. Accessed 10 Mar 2020

Nyoni B (2017) How Artificial Intelligence can be Used to Predict Africa's Next Migration Crisis. https://www.unher.org/innovation/how-artificial-intelligence-can-be-used-to-predict-africasnext-migration-crisis/. Accessed on 13 Mar 2020

Nzouankeu A (2019) App helps African farmers detect crop disease. https://www.voanews.com/ africa/app-helps-african-farmers-detect-crop-disease. Accessed on 17 Mar 2020

Omdena (2019) Using AI to predict climate change and forced displacement. https://omdena.com/ challenges/ai-climate-change. Accessed on 10 Mar 2020

One Concern (2020) What we do: We are advancing science based technology to make disasters less disastrous. https://www.oneconcern.com/product. Accessed on 16 Mar 2020

Oxford Insights International Development Research Centre (2019) Government artificial Intelligence readiness index 2019. https://www.oxfordinsights.com/ai-readiness2019. Accessed on 12 Mar 2020

Patrick S (2020) How should the world respond to the coming wave of climate migrants? World Politics Review. https://www.worldpoliticsreview.com/articles/28603/how-should-the-worldrespond-to-the-coming-wave-of-climate-migrants. Accessed on 15 Mar 2020

Peacock C, Mungai F (2019) Impact investment favours expats over African entrepreneurs: Here's how to fix that. World Economic Forum. https://www.weforum.org/agenda/2019/07/impactinvestors-favour-expats-over-african-entrepreneurs-here-s-how-to-fix-that/. Accessed on 12 Mar 2020

Penn State. (2019). New AI app predicts climate change stress for farmers in Africa: researchers will unveil their app for climate-smart agriculture to coincide with the UN Climate Action Summit. http://www.sciencedaily.com/releases/2019/09/190923082252.htm. Accessed 12 Mar 2020

Perrault R, Shoham Y et al (2019) The AI index 2019 annual report. AI Index Steering Committee Human-Centered AI Institute, Stanford University, Stanford. Accessed on 13 March 2020. Available at: https://hai.stanford.edu/sites/xg/files/sbiybj10986/f/ai_index_2019_report.pdf

Peters A (2018) This startup lets african farmers hire and on-demand tractor to boost their harvests. https://www.fastcompany.com/90227534/hello-tractor-and-john-deere-bring-10000-tractors-toafrica. Accessed on 20 Sept 2019

Petja BM, Malherbe J, van Zyl D (2004) Using satellite imagery and rainfall data to track climate variability in South Africa. Paper presented at the 2004 IGARSS 2004 IEEE International Geoscience and Remote Sensing Symposium, Anchorage, Alaska, 20-24 September 2004. https://doi.org/10.1109/IGARSS.2004.1369098

Pulse Lab Kampala (2018) Pulse Lab Kampala progress report 2016-2017. https://beta. unglobalpulse.org/document/pulse-lab-kampala-progress-report-2016-2017-2/. Accessed on 16 Mar 2020

Rasp S, Pritchard MS, Gentine P (2018) Deep learning to represent subgrid processes in climate models. Proc Natl Acad Sci U S A 115(39):9684-9689. https://doi.org/10.1073/ pnas. 1810286115

Scoones I, Thompson J (2011) The politics of seed in Africa's green revolution: alternative narratives and competing pathways. IDS Bull 42(4):1-23

Starbird K (2012) Crowdwork, crisis and convergence: how the connected crowd organizes information during mass disruption events. Dissertation, University of Colorado. http://fac ulty.washington.edu/kstarbi/starbird_dissertation_final.pdf. Accessed on 14 Mar 2020

TEDx Talks (2016) Predicting Africa's Next Refugee Crisis Using AI|Babusi Nyoni| TEDxCapeTown In: Youtube. https://www.youtube.com/watch?v=lsi8ZgTvbT4. Accessed on 14 Mar 2020

The Economist (2020) China's success on AI has relied on good data. https://www.economist.com/ technology-quarterly/2020/01/02/chinas-success-at-ai-has-relied-on-good-data. Accessed on 10 Mar 2020 
The Guardian (2017) 'Tsunami of data' could consume one fifth of global electricity by 2025 . https://www.theguardian.com/environment/2017/dec/11/tsunami-of-data-could-consume-fifthglobal-electricity-by-2025. Accessed on 10 Mar 2020

The World Bank (2014) Land and food security. https://www.worldbank.org/en/topic/agriculture/ brief/land-and-food-security1. Accessed on 17 Mar 2020

TOP500.org (2019) TOP500 lists. https://www.top500.org/lists/top500/. Accessed on 6 Mar 2020

Tortoise Intelligence (2019) The global AI index. https://www.tortoisemedia.com/intelligence/ai/. Accessed on 12 Mar 2020

United Nations World Data Forum (2018) (TA2.16) Earth observation applications for the sustainable development goals: opportunities for scaling successful methods. https:/unstats.un.org/ unsd/undataforum/sessions/ta2-16-earth-observation-applications-for-the-sustainable-develop ment-goals-opportunities-for-scaling-successful-methods/. Accessed on $16 \mathrm{Mar} 2020$

United States Environmental Protection Agency (2017) International Climate Change Impacts. Report from Climate Change Impacts edition of January 19 2017. Available at: https://19januar y2017 snapshot.epa.gov/climate-impacts/international-climate-impacts_.html. Accessed on 16 Mar 2020

Vodafone (2018) Vodafone Foundation to use aggregated anonymised mobile data to help prevent spread of epidemics in transformative 'Big data for good' programme. https://www.vodafone. $\mathrm{com} /$ news-and-media/vodafone-group-releases/news/vodafone-foundation-use-aggregate-data. Accessed on 15 Mar 2020

Weldemariam K, Pickover C, Kozloski J, Gordon M (2020) Artificial Intelligence for providing enhanced microblog message insertion, US Patent Application 20200028885, 23 Jan 2020

West D, Allen J (2018) How Artificial Intelligence is transforming the world. The Brookings Institution report. Available at: https://www.brookings.edu/research/how-artificial-intelligenceis-transforming-the-world/. Accessed on 04 Nov 2020

Open Access This chapter is licensed under the terms of the Creative Commons Attribution 4.0 International License (http://creativecommons.org/licenses/by/4.0/), which permits use, sharing, adaptation, distribution and reproduction in any medium or format, as long as you give appropriate credit to the original author(s) and the source, provide a link to the Creative Commons license and indicate if changes were made.

The images or other third party material in this chapter are included in the chapter's Creative Commons license, unless indicated otherwise in a credit line to the material. If material is not included in the chapter's Creative Commons license and your intended use is not permitted by statutory regulation or exceeds the permitted use, you will need to obtain permission directly from the copyright holder.

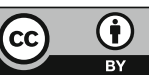

